\title{
Exploration of Practical Skills of College Students' Career from the Perspective of Psychology
}

\author{
Xu Suhua \\ Hanshan Normal University, Chaozhou, Guangdong province, China \\ Address: Xiangqiao District Bridge East Han Shan Normal College Dongli B District College of \\ Chemistry and Environmental Engineering Instructor Office, Contact: 13600125426;
} 527639962@qq.com; Post Code: 521041

Key words: career counseling; psychology; theory; thought; education

\begin{abstract}
Through the further analysis of the theoretical connotation and consultation technology of humanism theory, gestalt theory, existentialism theory, cognitive behavior theory and postmodernism theory, the author explores practical skills of college students' career from the perspective of psychology and constructs a scientific theory application system, which not only has a far-reaching impact on the college counselors who engage in student career counseling, but also has an important theoretical research value and practical significance.
\end{abstract}

\section{Introduction}

Since 2004, the national policy level of college students ideological and political education and mental health education attaches great importance to the implementation of the corresponding documents, stressed the need to build high-quality mental health education and mental health counseling workforce, in-depth and meticulous ideological and political work and mental health education, which correctly guides and motivates students and promote their growth. The goal of mental health education is to promote the development of mental health of college students. The task of ideological and political education lies in the value orientation of college students, and the two are interrelated with each other. National policy level of college students mental health education and ideological and political education gives an important support and guidance. In the course of implementing the practice of education, we should consider the theory of psychology as a guide in order to promote the mental health of college students at the same time to achieve the effect of value orientation of college students, contributing to a new way of thinking in current work of college students. This paper elaborates from the aspects of humanism theory, gestalt theory, existentialism theory, cognitive behavior theory, postmodernist theory and the theoretical connotation and consultation techniques, and tries to construct a scientific theoretical framework to change the past of giving personal experience to students on case counseling, promoting the situation of having a little effect on college students career counseling. It is of great significance to create a new situation and effectively promote the improvement of college students career counseling effect.

Humanism theory, gestalt theory, existentialism theory, cognitive behavior theory and postmodernism theory are very well-known and practical theory of psychology. From the psychological point of view of student confusion, the use of the relevant skills in psychological counseling for college students'questions and answer is a major innovation in the work of college student workers. The use of humanism theory can help to establish a good consultation relationship. Gestalt theory helps to clarify the problem. Existentialist theory helps to analyze the problem. Cognitive behavior theory effectively promotes the solution of the problem. Postmodernism Some ideas promote the generation of action. In the college students career counseling work, counselors often play the role of consultants, master the relevant theory of psychological school, and in practice sum up the use of ideological and political education to improve the effect of a multiplier effect. 


\section{Theory of Humanism}

\subsection{The establishment of the advisory relationship under the support of humanism theory} 2.1.1The Concept of Humanism Theory of Life. In the 1950s, American psychologist Maslow founded the humanistic psychology, which was greatly influenced by the third force of psychology, which emphasized the value of man, the meaning of life, the potential of man Self-actualization. Humanistic therapy plays an important role in college students' career counseling. It emphasizes that college students themselves are the first insiders of their own life and all feelings. They have the potential of self-understanding, self-cognition and self- When they are in an unconditional, positive relationship, this potential will be infinitely developed.

2.2 Theory of Humanism Career Counseling Perspective. The theory of humanism has a unique view on the function and function of the consultants. It is considered that the behavior and attitude of the consultants are much better than those of the experts who can solve the problem. Only when the good consultation relationship is created, the consultants can effectively use the Skills and methods, visitors can be multi-level to grasp the problem, the maximum degree of acceptance of the influence of counselor. Humanistic counseling methods focus on sincere communication with visiting visitors, so that visitors come to experience the various inner conflicts and uneasiness, understand their real needs, play their own potential, get rid of the value of others Standards to form a self-concept of habitual behavior, the objective positioning of their own, to determine their behavior value of the standard to reduce the behavior and their actual needs of the conflict may be, counseling counseling is to make the object in a safe environment close to their real needs, Into a person who can fully play their own potential. The biggest feature of the humanistic counseling method is. Therefore, the theory of humanism gives us such a perspective: college students in the student career counseling process plays a vital role in the process, with visiting students to form a "alliance", the attitude to be empathy, Sincere and unconditional respect for the students, through the teacher really concerned about, respect, understanding and acceptance of the attitude of visiting students to be able to relax the defense, into the internal thinking and exploration, hit the needs of college students, to solve specific problems An important guarantee.

\subsection{Second, The Reform of the Problem Under the Guidance of Gestalt Theory}

2.3.1Gestalt Theory of Career View. According to the Gestalt theory, people have the power to establish reciprocal links with others, to create a satisfactory life. Everyone can effectively deal with life problems, consultants just to help visiting the object aware of what is hindering their feelings and experience the current everything, so as to help visitors to enhance their self-perception, self-experience, self-experience ability. The method of consultation is basically non-explanatory, through the visitors to experience the conflict directly, the unknown part of the personality and fragmented part of the integration together [1].

Gestalt consulting technology career concept emphasizes living in the moment, that is too much into the past and worry about the future, are to escape the reality of the performance, vivid and directly face the experience at this moment, is the beginning of the effective role of energy. Indulge in the past aura effect and too worried about the future of employment pressure is the existence of college students who are two confusion, Gestalt theory to bring us inspiration, to guide students to focus on the moment, with the fastest speed and past farewell, Re-adapt to the university environment, find themselves in the environment of college students, reintegrate themselves from the negative part of the environment, from the support of the environment gradually turned to self-support, self-growth and problem-solving ability.

2.3.2Gestalt Consulting Theory Career Counseling Perspective. Gestalt theory in the consultation technology to emphasize the suspension of attention, consultants to do experience and insight with. In the case of good working coalition and consultation relationship has not yet been established, the visiting object has not yet stabilized and lacks a sense of security, it is not recommended to deal with the problems highlighted by the visiting object. To hang up, when the counselor is in sympathy, respect and positive attention On the basis of the internal stability of the visiting object, the negative emotions have eased, positive positive energy highlights the case, is to guide the object to deal with the problem of mature time, sometimes visiting the object of the 
problem is multi-level, but it is Interrelated, mutual influence, the consultation process to focus on a wide range of clues to start, it is necessary to pay attention to trauma, but also concerned about the real life, guide visitors to take the initiative to build a good social support system, planning future learning life.

Empty chair technology is commonly used in the format of the tower tower technology, this technology auxiliary props often used to two empty chairs, so that visitors have been sitting on two chairs, the two sides to experience the positive and negative role of the object to play the two To continue the dialogue, through this method, visitors can fully experience the conflict, in the role of play from different angles to accept and integrate different roles, so that the internal opposition and conflict to obtain a higher level of integration, learning to accept The other, and learn in the simulated environment to reduce sentiment and anxiety, master the skills of dealing with people, improve self-confidence. In the specific practice of college students' career counseling, the empty chair technique under the guidance of Gusta theory gives us such a view: for the specific problems of college students, such as interpersonal barriers, to guide the students to full the role of both sides Experience, feel the contradiction between the two sides of the position and emotions, from the role-playing analysis of the root causes of contradictions, from different angles to accept and integrate the role of conflict, to empathy against the contradictory body, while resolving the dispute while relieving emotions, Communication barriers, in the care of career counseling, enhance confidence and enhance interpersonal skills.

\subsection{Third, the Use of Existentialism in the Analysis of the Problem}

2.4.1The Existentialist Theory of the Concept of Life. Due to the social transformation and the influence of multiculturalism, the traditional values are greatly affected. College students are in the critical period of the formation of values, for their own understanding of the existence is not comprehensive, in the survival of the tide and material tide, it is easy to forget the meaning of existence. There are many college students who have a sense of emptiness, a sense of lack of sense, which is typical of Franklin's presence of neurosis [2].

The theory of existentialism tells us the unique view of life: our task is to create a meaningful and purposeful life; we have the right to choose freely, while at the same time to be responsible for their own choices and actions, freedom and responsibility forever linked to escape responsibility The freedom must produce anxiety, the courage to take responsibility is to eliminate the premise of anxiety. People are often unbearable not painful, but meaningless, and when we begin to accept our responsibilities and give pain and challenge to a valuable meaning, we begin to learn to embrace the uncertainty of life. Learning to choose, learn to assume, to seek a consistent with their own survival values or construct the new meaning of life is an important driving force to change, but the choice and commitment to the premise is a reasonable understanding of the decision. Any decision is risky, there is no perfect decision, decision-making is based on the current information and personal judgments, towards the future to risk, decision-making ability to determine a person's career maturity.

2.4.2Careerist Theory of Existentialism. Existentialism in the process of analyzing the problem for us to provide a four-way decision-making model, to visit the object clear four factors: time, decision-making power, ideas, goals and so on. Time decision on how long this decision, to do the final decision to the final time of the final line; for the question asked, how much discretion to choose, is a decision-making problem or an adaptation problem, if it is a decision-making problem, It is a decision-making or two-level decision-making, if it is a decision-making, it is necessary to do the option, if it is a secondary decision, it is necessary to do the choice of response methods. For this issue, others will give advice on what, combined with the recommendations given by others, the formation of the views of their own visitors, clear their desired goals, across the options to see the target, the object can be an effective selection of options.

Most students in the face of career decisions are more or less there are some confusion, suffering from career decision-making difficulties, there are many students on the implementation of career decision-making is not strong, the goal is difficult to complete, resulting in frustration. First-line counselor work often face students a variety of decision-making confusion, for example, whether to 
turn professional, whether Kaoyan, whether research, whether love, whether to run student cadres and other issues, if you can use the theory of careerist counseling perspective, It is of great practical significance to promote the students' rational decision-making, to take responsibility for responsibility and to gain and grow. It is of great significance to solve the problem of the problem.

\subsection{Fourth, Cognitive Behavior Theory from the Perspective of Problem-solving Model}

2.5.1Cognitive Behavior Theory of the Concept of Life. Cognitive behavior theory is composed of a variety of cognitive theory and behavioral theory, mainly cognitive treatment, but also take into account the behavior of correction, belonging to a certain degree of integration of psychological treatment theory. In the consultation process, the problem as the center, by changing the unreasonable cognitive concept in order to achieve the effect of correcting emotional behavior. Therefore, the application of cognitive behavior theory in college students practice with strong practice, high flexibility, treatment and consultation with the use of strong features.

Based on the cognitive psychology of counseling methods are reasonable emotional therapy (REBT) and cognitive behavior therapy (CBT) two. Reasonable emotional therapy (REBT) in the 20th century, 60 years has been swept the world, it is by the famous American clinical psychologist Dr. Ellis in 1955 put forward, his famous view is: "people are not troubled by things, (CBT) is based on the cognitive treatment technology established by American psychologist Baker in 1976, which is absorbed by mutual recognition of cognitive theory and behavioral therapy, and mutual recognition of cognitive behavioral therapy (CBT) Supplement the formation of the system of treatment [3]. Cognitive theory holds that the cognitive process is determined by emotions and behavior. The cognitive process determines the behavior of the behavior. At the same time, the change of behavior can also influence the process of cognition, provide evidence to the original cognitive concept and make it more Consolidate and conceal, making the problem more and more serious. Cognitive behavioral therapy is to improve the cognitive concept of unreasonable cognition by correcting the technology, and to link cognitive correction with behavioral correction at all times, and strive to establish a virtuous circle between the two to replace the vicious circle, So that the original bad symptoms to reduce, disappear.

2.5.2 Six Theoretical Perspective (b) Cognitive Behavioral Problem-solving. From cognitive behavioral psychology theory "myself," "bystander", "relevant persons", "Camera", "role model", "future" and other six perspectives, analyze and solve problems, "my own" from a subjective perspective, without considering other factors, entirely from his heart, the rational part of the closure, in full accordance with their own ideas instinct to act; "bystander" from an objective perspective, if you are a nobody any relationship with this thing, how to treat this problem; "relevant persons" to consider the issue from the perspective of empathy, if the relevant person from the point of view of the event, there will be what kind of feelings and suggestions; "camera" is presented from the perspective of development from the past to the Now the picture, feel the deepest picture, showing the future desire to see the lens; "example" from a positive perspective, analysis of those who deal with these aspects of the problem is more experienced in the more admired or admire where people can get What advice; "future" from results-oriented perspective, if this thing is over, we stood back to see a future, What the thinking and discovery; Perspective Based on the above multi-angle depth analysis of the problems they face, perspective essence of the problem, the best ideas come to solve the problem and the best solution.

Cognitive behavioral psychology theory in college students career counseling provides us with a perspective: to confuse college students is often not the problem itself, but the view of the problem; college students emotional response and behavior, depending on their inner basic Beliefs; for the individual students, they have a natural self-growth and self-realization needs, but they often use the acquisition of the frustration model hindered the development of self; they have self-talk, self-evaluation, self-sustaining ability. Through counseling, so that students visit a more realistic, more effective cognitive model, so as to minimize their emotional disorders and self-defeated behavior. Once the visiting students begin to understand - emotions and behavior are determined by their beliefs, they can be effectively involved in the process of their reconstruction.

\subsection{Fifth, Postmodernism Theory to Promote the Role of Action}


2.6.1 Postmodernist Theory of Career View. Postmodernism is a kind of art, social culture and philosophy that prevailed in Europe and America in the 1960s and 1980s, breaking the traditional rational idea, criticizing rationality, not only concerned with the relationship between subject and object, But also concerned about the relationship between the main body, the subject and the society, with different from the traditional rationality of the subjectivity and communication rationality to reinterpret the modernity [4]. Postmodernism that things do not have the only standard answer, advocate a wide range of innovative thinking, the pursuit of human personality and ideological emancipation, improve people's innovative spirit and dialectical thinking ability.

The positive influence of postmodernism thought makes the value orientation of college students more rational, more open thinking, full respect for the development of college students' personality, guide students to face the society, the courage to expose the bad phenomena in society, improve the ideological consciousness of college students and emphasize the main value. The positive influence of postmodernism on college students after 90 is conducive to the cultivation of innovative spirit of college students, advocating the individual to give full play to imagination and creativity, to diversify the understanding of things, to promote breakthroughs in traditional way of thinking. It is conducive to cultivating college students to form the concept of harmony between man and nature, man and society, man and nature. Postmodernism advocates college students in interpersonal communication should have an inclusive mind, equal dialogue, willing to listen to other people's voice, good at learning the advantages and strengths of others.

2.6.2 A Career Perspective of Postmodernist Theory. Focus on short-term therapy (SFBT) is based on post-modernist counseling methods, the current academic more popular and practical [5]. SFBT consulting method has the characteristics of practicality and flexibility, in the course of the process varies from person to person, there is no unified model, advocated to actively encourage and carry forward the advantages of the main characteristics, starting from the positive significance, advocate development orientation, efforts to increase Expand the white spots, black spots naturally less and less. The SFBT consultancy also advocates the importance of focusing on small successful experiences, believing that a small start is half of the success, and small goals can lead to confidence and motivation in case resolution, especially where the first small change is a success Example, it is easier to act, the therapy in enhancing the self-confidence of students, to encourage enthusiasm has a very significant effect.

Robert Dirz combs the six logical levels of postmodernism's action, namely: the vision - the role of positioning - to clarify the values - to improve the ability to promote action - a clear environment for college students Career counseling, to promote the success of the action has brought a new perspective: the first step to lead students to show their inner expectations, into the imagination, to experience the ideal state, including the imagination to see the wonderful picture, hear the sweet voice, To the comfort experience, to stimulate students to solve the problem of motivation. The second step to guide students to the role of positioning, imagine the ideal state of their own roles, including identity, job, title and other information and role experience. The third step clarifies the motivations and meanings, values and reasons behind the choice of students. The fourth step is to focus on the ability of students to visit their own existing and still need to improve. Step 5 Develop specific programs and programs to guide action. Step 6 Let the program, plan, action landing, clear action environment, including action time, place, process and related person. Postmodernist theory gave college students a profound inspiration, told us to keep curiosity, our accumulated knowledge and experience belong to the past, in front of visiting students is their own experts, when we are willing to a "unknown "The attitude into the consultation, we can really come into the inner world of visiting students to help them solve the problem.

\section{Summary}

In accordance with the guidance of the "Regulations on the Construction of Counselors in Ordinary Colleges and Universities", counselors should "strive to become students' life instructors and healthy friends of healthy growth", and strive to become the helpers of students, The theory of humanism, the theory of existentialism, the theory of existentialism, the theory of cognitive 
behavior, postmodernism and other theoretical connotation function, commonly used technical methods, The idea of solving the problem and so on, and explores the technical methods of the practice of college students 'career problems, try to construct the scientific theoretical framework, and hope to promote the effective promotion of college students' counseling effect, for the ideological and political education of the first-line college students, Is the counselor to provide theoretical support and technical support for college counselors engaged in student career counseling counseling has far-reaching impact, but also has important theoretical research value and practical significance.

\section{Fund Project:}

This article is the exploration and practice of the operation mode of the students' development model of the ideological and political project of Hanshan Normal University (project number: SZ201603).

\section{References}

[1] Yan Ming. Based on the theory of Gestalt on a psychological trauma students advisory report. Nanjing Xiaozhuang University .2016 (1)

[2] Kang Jiqin. Existentialist group counseling in the application of college students. Old area construction .2013 (6)

[3] Liao Shuli et. Application of cognitive behavioral therapy in nursing Alzheimer's disease. Chinese Journal of Clinical Nursing .2015 (3)

[4] Huang Linqing et. The influence of postmodernism on college students' values. Economic and social .2015.13 (6)

[5] Chen Wu et. Science and education guide. Education narrative in the growth of college counselors in the value of . 2014 (1) 